The remaining papers before the Section were :-Prof. J. P. McMurrich on some points in the symmetry of Actinians ; Prof. Lloyd Morgan on the natural history of instinct; Mr. W. G. McCallum on the hæmatozoon infections of birds; Mr. J. Stafford on the post-embryonic development of Aspidogaster conchicola, and Mr. G. P. Hughes on the antlers of the red deer, and on the evolution of the domestic races of cattle. Prof Lloyd Morgan, in his paper on "instinct," replied to certain criticisms of the biological treatment of instinctive activities as relatively definite organic responses. Mr. Rutgers Marshall had argued that the "instinct of self-preservation," the "play instinct," and so forth, could not be regarded "as in any sense definite. Prof. Morgan contended that these are group-terms under which a number of responses, each in itself relatively definite, are roughly classified. If we speak of " mimicking instincts" the group is so varied as to be quite indefinite as organic response. But when we study the particular cases which fall within the group, we find that each example shows an activity of a relatively definite kind.

The Section did not meet on Wednesday, as another natural history excursion was planned for that day in conjunction with Section K. It seemed desirable, to the biologists, on an occasion when the meeting was held out of Britain, that every opportunity should be taken of studying the more or less novel fauna and fora. This field work has been continued by some naturalist on the excursions which concluded the meeting. Thus Prof. Miall and Prof. Ramsay Wright have gone to examine the Algonquin Lakes; Prof. Herdman has been dredging and townetting in Puget Sound on the Pacific coast ; while Profs. Bower and Marshall Ward have been collecting plants; and Prof. Poulton insects at many points along the line from Toronto to Vancouver.

\section{PHYSICS AND CHEMISTRY IN RELATION TO MEDICINE.}

THE advances of medical science due to the adoption of the methods and results of physics and chemistry have recently been generously acknowledged by several foremost members of the medical profession, in addresses delivered before congresses, and at the opening ceremonies of various medical schools on October I. From the reports of a number of these addresses, the subjoined expressions of opinion have been collated. It is gratifying to be able to put on record these authoritative views as to the assistance which the physical sciences have given to medical progress.

Medical Progress due to Physica, and Chemical Methods. ${ }^{1}$

All recent progress in medicine has depended on research and discovery carried on by physical and chemical methods. The mechanical principles that were first applied in anatomy, the mother science of medicine, to the explanation of the construction and movements of bones and muscles have been carried by the physiologist into every organ of the body and into the arcana of the tissues, and have been shown to be essential to the understanding of the changes that take place in them during the performance of their functions. And at the same time the aid of chemistry and electricity has been invoked to drive back step by step, and if possible to banish altogether, that vitalism which was at one time all but supreme in the domain of animal physiology. And now, not content with this corporeal conquests, the physiologist is pushing his mechanical methods into the realm of psychology, and is seeking by means of them to investigate the data of consciousness. Having by electrical stimulation and other experimental procedures localised sensory and motor centres in the brain, having shown that there is a definite order of development in the nerve tracts, and having disentangled to a large extent the paths of nervous impulses of various kinds, their halting points and goals in nerve cells, he is now eager to catch ideas on the wing and to examine them in the usual manner. Helmholtz, in his great works on vision and hearing, was the first to show how physics mount into physiology and psychology, and after him Weber, Fechner, Lotze, and Wundt have step by step pushed forward the parallels of the material accompaniments of thoughts and feelings. And quite recently a

1 Extracted from an address on "Ethics and Individualism in Medicine," delivered at the opening of the winter session of the Queen's Faculty of Medicine, at Mason College, Birmingham, on October I, by Sir James Crichton-Browne, F.R.S

$$
\text { NO. I } 458 \text {, VOL. } 56]
$$

movement has sprung up in Germany to advance still further mechanical explanation of the facts of mental life, and to bring psychology, which has always been scientific in as far as it has observed and classified and analysed phenomena, into line with the exact sciences of external nature. Experimental psychology has been inaugurated, and research laboratories, in which the physical and vital changes that are associated with mental processes are to be measured and tested, have been establislied. Originating in Leipzig, experimental psychology has taken root in several other centres on the continent, has spread to America, where it has been eagerly adopted, and has at last made its way into England. The University of Cambridge has voted a sum of money to be devoted to investigations in connection with it, and a few months ago a meeting was held in London to promote the establishment of a laboratory for its study in University College. The names of those who attended that meeting are a sufficient guarantee that the project which it approved will be successfully carried out. I have little doubt that suitable arrangements will be made for instruction in the new methods of psycho-physical research in University College, and that in course of time other schools and colleges-Mason College amongst them-will follow its example and afford facili. ties for studies in anthropometric psychology. I have little doubt, too, that such studies will be fruitful of useful results, by widening the scientific basis of psychology and supplying us with standards by which to gauge the speed and duration of certain neural operations, the variations in these in different ind ividuals, and the depth of certain mental defects. But at the same time I am disposed to think that exaggerat ed notions are entertained as to what experimental psychology can actually accomplish. Its field is, after all, a narrow one. It can never supplant self-observation and introspection as means of mental analysis, and must indeed always to a large extent lean on these. It is practically restricted to the measurement of sensations and movements and the gaps between them, or the simplest mental processes; and hitherto it has, it must be admitted, been somewhat ambiguous and indefinite in its declarations. For my own part I look with more sanguine expectations of light on the obscure problems of mind to comparative, ethnical, developmental, and pathological psychology - which may all, of course, be investigated by experimental methods-than to the new experimental psychology strictly so-called.

We all gratefully acknowledge the immense debt we owe to experimental physiology with its exact mechanical methods. It has dispelled myths and errors, supplied us with a body of precise and well-organised knowledge, and revolutionised our treatment of disease ; and it promises in the future not only to augment our healing power, but to afford trustworthy guidance in education and in the regulation of some social relations. As it stands to-day physiology, it seems to me, offers a liberal culture to all who study it. An independent science itself, but in touch with all other sciences, it brings into exercise observation, judgment and memory, while it passes in review questions of surpassing interest to every human being, and thus confers an admirable intellectual discipline while storing the mind with information that must prove useful in the conduct of life.

\section{Scientific Method in Medicine. ${ }^{1}$}

Various spheres of activity have exercised their influences in bringing medical science to its present position.

We must, in the first place. ascribe the greatest importance to the study of anatomy. Gradually our knowledge of every detail of naked-eye anatomy has been gained, and at the present time every one practising medicine must have a competent knowledge on the subject gained by dissection. The same systematic study has extended to comparative anatomy, and great, for its time, as was the knowledge of Aristotle, it has undergone an entire revolution by the application of scientific methods to increased data of information by such workers as Cuvier, Darwin and Owen. It is now taught as a branch of medical education. Physiology could have no scientific basis until anatomy was fairly advanced The facts on which it was at first based were founded on medical observations, but in the seventeenth century direct investigations and observations were commenced by Haller, Hunter, Spallanzani and Hewson. It has since been prosecuted with the greatest zeal and success, and the position of physiology

1 "The Influences that have determined the Progress of Medicine during the preceding Two and a half Centuries." Abridged from an address delivered at the opening of the Section of Medicine, at the annual meeting of the British Medical Association at Montreal, September 1897 , by Dr. Stephen Mackenzie. 
at the present time is that of a science, explaining the action and interaction of the organs and tissues, and the forces of the body, which is the true foundation of scientific medical knowledgethe Institutes of Medicine. The rise of physics and chemistry in the seventeenth and eighteenth centuries contributed greatly to the progress of medicine by increasing our powers of "searching out the secrets of nature" by methods and instruments of precision.

Of any one influence that has helped the advance of scientific study and the progress of medicine probably the increasing perfection of the microscope has been the greatest. With each new development of this instrument a greater range has been given to our researches, and with the assistance of chemistry it is continuing to reveal to us fresh facts that have created new branches of science.

Starting from the observations of Bichat on the minute anatomy of the tissues in $180 \mathrm{or}$, the microscope has enabled us to understand the details of structure which were essential to complete anatomy. Until the microscope was capable of practical use the capillaries could not have been discovered by Malpighi, nor the composition of the blood understood; the mechanism of renal secretion could not be worked out until the minute structure of the kidney was known; the functions of glands, the process of digestion and secretion could not be understood until the histological details of the parts concerned were ascertained; the mechanism of light and hearing, of taste and smell were not revealed until the ultimate details of the structures involved had been investigated; the marvellous complexity of the nervous system, whether in the delicate though comparatively coarse structure of the nerves, the higher intricacy of the spinal cord, and the marvellous details of the arrangement of ganglionic cells and communicating fibres of the cerebral tissue, which by improved methods of preparation and staining are being revealed to us at the present time, could not have been worked out without its aid. Just as anatomy had to reach a certain stage before physiology and morbid anatomy became possible, so normal histology had to advance before pathological histology could come into existence; and as knowledge advances from the special to the general, special pathological histology had to reach to a very high point before we could reach that knowledge of general pathology on which our conceptions of the nature of disease are at present based.

The microscope again has introduced us to a new world, revealing minute organisms that play a great part in the plan of nature, and which are largely concerned in the production of disease. It has led to a new department of science, bacteriology, which has taught us how bacteria enter the body, how they increase and multiply therein, and how the tissue reacts for for self-protection. Chemistry has shown how the poisons formed by such organisms act in the body, and supplied us with means-as yet only in their infancy-for counteracting their effects or guarding against their exclusion and by protective inoculation. The microscope has further furnished us with evidence of parasitism other than bacteria in the blood, in the muscles, in the skin and hair, and on the mucous membranes. By its aid we are able to diagnose and watch the course of several primary diseases of the blood. It has enabled us to differentiate the various new growths that develop in our bodies. So much does the microscope constitute a necessary means of research that it would be impossible to perform our daily medical duties conscientiously without its aid.

The thermometer, again, has been of invaluable aid in the study of disease, allowing of our measuring and recording the degree of fever, and of watching its progress with such a degree of accuracy as to furnish us with evidence of the greatest value in the diagnosis, prognosis, and treatment of disease.

Electricity, by the laborious and complete investigations of Du Bois-Reymond, has revealed to us the mode of action of nerve and muscle that would have been impossible to obtain in any other way. Though the hopes at first entertained of its value in the treatment of disease have not been altogether fulfilled, it is still of much service in this respect, and perhaps still more valuable as an aid in diagnosis.

The ophthalmoscope, introduced by Heimholtz, has enabled us to understand diseases of the interior of the eye, which, without its assistance, was impossible. It has admitted of the exact examination of refraction, and has revealed changes in the termination of the optic nerve, in the retina and choroid, rot only valuable in themselves, but so important in the light they throw on pathological changes occurring in the nervous system, and in the body generally, that the use of this instrument has become a necessity of practical medicine.

The laryngoscope perfected by Czermak has given a precision to the diagnosis and treatment of diseases of the throat not otherwise attainable, and which has important bearings on general medicine, by the recognition of paralyses of the muscles that move the vocal cords in aneurism and in disease of the central nervous system.

The sphygmograph, the cardiograph, the arteriometer, and, the latest invention of this class, the sphygmometer, have enabled us to ascertain the exact condition of the circulatory system, of the greatest service not only in studying the problems of normal and abnormal physiology, but in the recognition of disease and its tendencies, and in the influence of remedies.

All the branches of scientific knowledge we have been considering - anatomy and physiology, chemistry and physics, morbid anatomy and pathology, therapeutics and preventive medicine-have helped us to the knowledge we at present possess. But they have rendered a further aid to medicine than the mere knowledge they enabled us to acquire. Them. selves scientific studies utilising methods and instruments of precision, they have influenced our whole mode of thought, and made us exact and precise in our observations and investigations of disease. We may paraphrase an expression of Burdon Sanderson's: "The history of modern medicine is largely the history of scientific method." So when we are taunted with the assertion that medicine is not a science, we can reply that medicine utilises the knowledge gained in every branch of science, and is scientific in its method of research into the nature and treatment of disease. If its results are not so exact as in some other branches of knowledge, this is not due to any want of scientific method and care in its investigations, but to the very complicated phenomena with which it has to deal, whilst the investigator has not the same unfettered freedom of dealing with his subject that the investigator into chemistry or physics has. By a continuance of the same methods and exact research; we cannot for a moment doubt that the progress that has beer. so manifest in the past will be exceeded in the future.

\section{The Influence of Chemistry upon Medicunal Treatment. ${ }^{1}$}

We must recognise that until the most recent times all remedies were borrowed from the purest empiricism. Unprejudiced physicians, armed with the weapons of scientific criticism, disentangled popular observations from superstitious and mystical ideas, and put to actual clinical test measures vaunted by their conservative colleagues, in order to ascertain whether in reality any use could be made of them. In consequence of the early state of scientific knowledge their judgment had necessarily to be based entirely on the results of practical experience without any experimental assistance. In this connection the history of digitalis is most instructive. Withering finds an old family recipe for dropsy; he does not keep to him. self the results obtained with it, he finds the remedy of actual value, and in 1785 publishes it, with the results of his own cases, and so introduces it into practice.

It is extremely interesting that even the action of many of the chemical elements has been made use of in the form of the simplest house remedies. The ashes of the ordinary marine sponge have, for example, been much employed on account of their curative properties. When, however, chemical analysis found that they only contained soda, this valuable remedy, which had also found its way into medical practice, was for some decades laid aside. For in that period of chemical knowledge the mistake began of relying too much upon analytical results and of disregarding the strong evidence of clinical experience, because analysis did not necessarily detect powerful substances to explain the action of remedies. Owing, however, to the valuable discovery of Courtois, the soap-boiler, who separated iodine from the soda-lye of his factory, it was easy to demonstrate this element in sea sponges as well, and it had in consequence to be admitted that the results recorded with them were neither due to error nor to suggestion. And how noteworthy is it that in opotherapy also iodine was first discovered long after its value

1 Abridged from an address on the Aims of Modern Medicinal Treat. ment, delivered at the Fifteenth Congress of Clinical Medicine at Berlin by Prof. Dr. Oscar Liebreich. 
had been shown by therapeutic observations, made in ignorance of the fact that an iodine-containing organic body was present in the thyroid. Similar considerations apply equally to preparations of arsenic and mercury. It could not but happen that the philosophic point of view ascribed to all these remedies certain qualities which did not in reality reside in them. It is admitted, however, that the idea that as a matter of fact the chemical properties of a substance were of significance in regard to its action was known to Paracelsus. If, therefore, the fanaticism for this idea far overshot the mark, still the results then and afterwards obtained, and, indeed, the whole work of the iatrochemical school was not without therapeutic value.

The science of experimental pharmacology, which has arisen in our time, might well have contented itself with undertaking to put to the test the therapeutic material already to hand, and to contribute to the elucidation of its mode of action in order to be able to lay down more precisely the limits of its action, and so to lend a helping hand to clinical observation. It could easily have foregone the further empiricism of collecting new materials. But from the moment in which scientific remedies were brought into the domain of therapeutics, its horizon widened. It became necessary to take up and to seek to realise the idea of freeing the mind from empiricism, and of finding the leading principles by which the material of the healing art might be increased in a scientific manner. With the beginning of the attempt to establish this undertaking pharmacodynamics could no longer be satisfied to use merely the results of simple experiments upon living animals, but must needs also, with scrupulous attention to pathological principles, regard as its most important factor the representation of the conditions in health and disease as the basis of experimental inquiry.

In so far as concerns the search after new materials for remedies, one may correctly rely upon the principles of the iatrochemical school. Only those ideas must be excluded which, owing to deficient anatomical knowledge, rank as belonging to humoral pathology in the most rabid sense of the term. The investigators of those days stood also in the shadow of an alchemical environment, but had always before their eyes the endeavour to form an idea as to the nature of matter. For us, modern chemical ideas have created a new world. We know now that the smallest part of a chemical component-let us say, for example, a piece of sugar-is characterised by a special arrangement of the atoms of various elements, and that each change in their relative positions leads to the formation of a substance with new physical properties. The development of chemical research in this direction points to the discovery of innumerable new substances. One single reaction can yield several millions of these, and he who knows how to use the pencil aright can readily, by the construction of their formulæ on the paper, convince himself that the vast number of hitherto, isolated organic substances forms but a minute part of those which can be assumed with safety to be capable of existence. This simple observation teaches us that we are no longer travelling along the route by which digitalis and the other old remedies of the healing art were made known to us.

It is very noteworthy that a long period elapsed before attention was paid to these powerful therapeutic adjuvants. It may be acknowledged with great thankfulness that this attention has been directed not only from the medical but also from the chemical side. In this connection, A. W. v, Hofmann correctly points out that after the discovery of so many organic substances some were soon brought into use for the sake of their external properties, while their internal applicability was never troubled about. Thus chloral hydrate was discovered in 1832 , but its properties were first recognised through my pharmacodynamical researches in 1869 . When new alkaloids were discovered, the task which lay before the chemist was to test their action upon the organism itself on the chance that it might fit in with a similarity in chemical constitution between their new substances and alkaloids. On account, however, of defective application of methods which lay out of their own beaten track, many chemists overlooked the true affinities of these bodies. In support of this may be adduced an example which has hitherto been scarcely ever quoted. Cocaine was discovered in Wöhler's laboratory. Its chemical similarity to atropine led to a chemical investigation of its topical action on the eye, and while it was noted that no dilatation of the pupil occurred, its remarkable property as a local anæsthetic was overlooked.

$$
\text { No. [ } 458 \text {, VOL. } 56]
$$

Even the chemists found soon enough the exceptional loss of sensibility which cocaine causes when applied to the tongue; but it was Koller's medical observations and the clinical observations following which first indicated the correct position of cocaine as a drug.

The first ideas in testing the materials provided by chemistry in such enormous quantities must naturally be directed towards establishing a connection between their chemical constitution and their action. And from this line of thought many considerations naturally result. Before everything, it compels the speedy observation that the chemical division into groups such as alcohols, aldehydes, ketones, \&c., has no bearing upon therapeutical action. Nevertheless, that a connection exists between the actions of certain chemical groups is not to be denied. It has been proved that the great group of bodies allied to antipyrin ("pyrazolones") exhibit similar therapeutic properties in a given direction. But we must always keep in mind that when we wish to speak of the connection between constitution and action, we must recognise that the effect of medicinal action upon the animal and human frame forms a complex whole, and cannot be mapped out with mathematical clearness. Bodies which lower the temperature produce an effect which is compounded of various different factors. The same is true of the lowering of blood pressure : thus one cannot scientifically represent that the chemical constitution of a given substance will be in relation to its influence on a complicated diseased condition such as migraine, or perhaps on the killing of the itch parasite, the destruction of which can be accomplished by the most varied toxic agencies. This imperfection of the new method must be admitted, but from its incompleteness no one can deduce that it is useless. On the contrary, its perfection promises to bring forward new and unexpected results.

But it must also be admitted that if the knowledge of the chemical material be made the basis of research and merely taken by way of comparison in relation to the remedies already guaranteed by experience, this alone already affords sufficient ground for rendering a portion of the chemicals available in treatment. In this connection I may recall, for example, the fact that working from the chemical constitu. tion of cocaine bodies, such as eucaine were obtained which are not, it is true, identical in action with cocaine, but are able to replace it in many cases without exhibiting its toxic action. Thus in the search for new remedies it is no longer indicated that we should wait for chance results, as was formerly the case; we are, on the other hand, directed by scientific principles. Results crowned with success may be obtained through the most varied combinations which only those ignorant of the scientific method could describe as a " happy chance."

\section{The Pursuit of Natural Knowledge. ${ }^{1}$}

After referring to the history of University education in England, and congratulating Sheffield on the union of Firth College and the Medical School to form the new University College, and on its approaching admission as a constituent of the Victoria University, Dr. Pye-Smith said enough probably had been done for the present in constructing the framework for higher education in England. Accumulated endowments were still needful and the working out of the federal type of university. If he might offer advice drawn from the chequered and still uncertain fortunes in London he would say-trust to local wealth and public spirit and avoid Government grants as much as possible. Beware of the utilitarian spirit ; let adequate provision, personal and material, be made first for literary and scientific research, secondly for educa'ion, and thirdly for technical instruction. The reversed order was the easier, but in the long run he ventured to think the less fruitful. While the moderating influence of statesmen and men of business and the interest and support of past students and graduates would find a valuable place in the constitution, let the chief responsibility rest upon those actually engaged in teaching and research.

Dr. Pye-Smith then went on to speak of the two senses of the word knowledge, both of them the objects of attainment by students of a university. The desire for knowledge how to do something is historically the earlier and is shared to some extent by the lower animals. Its end was: subjectively, the partly physical, partly intellectual pleasure of exercising the 1 Abstract of part of an address delivered at the University College Sheffield, by Dr. Pye-Smith, F.R.S. 
muscles and brain ; objectively, the attainment of some useful object. Such knowledge was called skill or art, and the man who attained it was a skilled workman, an artisan, an artist, a master of his craft. The continuity of this kind of knowledge depended on tradition, and its improvement was by invention. Its acquirement was called technical education; its results were seen in the products of agriculture which feed us, in the ships and railroads which carry us round the globe, in the triumphs of steam and electricity, of preventive medicine and antiseptic surgery, in the matchless steel, the wondrous armour-plates, and all the vast output of the skilful industry of Sheffield. But there was another kind of knowledge - the desire for which came later in human history - the knowledge of what things mean, of how they consist, of why one event follows another. This knowledge was not active, but contemplative, not practical, but theoretical, not technical, but scientific. Its end was purely intellectual; subjectively, the pleasure of exerting the mental powers; objectively, the truth about things. We call this knowledge science; that is, not only acquaintance with the objects around us, or natural history (descriptive botany, zoology, mineralogy, geology, astronomy, and anatomy), but also some insight into their constitution and growth, into the laws of their origin, their actions, their decay and metamorphoses. This was called natural philosophy. Its improvement depended, not on invention of tools and methods, but on discovery of facts and their relations. It was only indirectly useful, and the pleasure it gave was in proportion to the intelligence of the man who felt it : "Felix qui potuit rerum coynoscere causas." The abstract sciences seem to have arisen out of the needs of useful arts-geometry out of measuring the rising of the Nile, arithmetic out of counting the hosts of a Persian despot or the gains of an Indian money-lender, trigonometry out of setting landmarks, chemistry out of the alchemist's search after gold, botany out of materia medica, and anatomy out of surgery. Amply has the debt been repaid. At the present time all the progress in useful arts was called "scientific," and rightly so, for all depended upon natural science. Agriculture rested on the basis of organic chemistry, geology, and botany, navigation on astronomy, the working of metals on physics and chemistry, engineering on mathematics, medicine on physiology, and if ever the art of governing mankind was to be more than empirical, it would rest on profound knowledge of palæontology and neuro-physiology.

\section{UNIVERSITY AND EDUCATIONAL} INTELLIGENCE.

CAMBRIDGE.-On October I, the first day of the Michaelmas term, Dr. Alex Hill, Master of Downing, was formally admitted to the office of Vice-Chancellor. The retiring Vice-Chancellor delivered an address to the Senate, in which he reviewed the events of the past academical year. The emphatic rejection of the proposals in reference to degrees for women rendered it probable that some years must elapse before the University would grant any further rights or privileges to women students. The statement published last term by the Chancellor, as to the pressing financial needs of the University, had already led to one munificent gift of $2000 \mathrm{l}$., and it was hoped that this would be followed by others. Valuable donations to the museums and laboratories were acknowledged. Among new appointments were included the Professorship of Mental Philosophy, the Gilbey Lectureship in Agriculture, the Lectureship in the Hausa Language, and the Lectureship in Physiological Psychology.

The death of Prof. C. S. Roy, F.R.S., who has filled the chair of Pathology since 1884, took place on October 4. The late professor has been incapacitated by serious illness for over a year, but his death was somewhat sudden. The department has been superintended during his prolonged absence by Dr. Kanthack, of St. John's College, the deputy-professor.

IT is stated in Science that the plans are well formulated for the proposed new physical laboratory of Dartmouth College, New Hampshire, the result of the 75,000 dollars bequest of the late Mr. Charles T. Wilder. The committee has set apart 50,000 dollars for its erection and 20,000 dollars for maintenance. Additional grants have been made for an observatory, the foundations for which will be laid at once.
Prof. G. B. Howes presided at the annual meeting for the distribution of the prizes gained by the students of the Westminster Hospital Medical School, on Thursday last. Reference was made in the report, read by the Dean of the College, to the resignation by Dr. Dupré of the post of lecturer on chemistry after thirty-three years' service, and it was stated that he had been succeeded by Dr. Wilson Hake. The entrance natural science scholarship, value $60 l$, was awarded to Mr. E. C. Whitehead, and the entrance scholarship of 40 l. to Mr. F. D. Martyn.

Mr. R. C. Christie has given to Owens College, Manchester, the whole of his share of the estate of the late Sir Joseph Whitworth, as residuary legatee. It is estimated that the value of the gift is $50,000 l$. Mr. Christie has expressed the desire that the sum should be devoted to the erection of such buildings as the governors should think fit in connection with the college, only stipulating that the name of Sir Joseph Whitworth may be associated with the new buildings, and that they may be accepted and treated as a further gift from him to the college. It is also announced that two friends of the college have given sums respectively of $20,000 \%$. for the erection of a physical laboratory and $5000 l$. for the maintenance of it; also that Mr. Edward Holt, of Manchester, has sent a cheque for 1500 . towards the erection of a museum at the college. Mr. Christie's fund will probably be devoted first of all to the erection of a hall for ceremonial and other large gatherings at the college.

Mavy of the syllabuses of the subjects in which examinations are held by the Department of Science and Art have been modified. As already announced, the examinations in the honours stage of most of the science subjects will in future be divided into two grades : Part I. of a more advanced character than the advanced stage ; and Part II. dealing with the highest branches of the subject. The honours portions of the syllabuses of most of the subjects have been re-written in consequence of this new regulation. The syllabuses of naval architecture, applied mechanics, and general biology (Section I.) have been entirely re-written. Prof. J. Perry is now an examiner with Mr. W. H. Greenwood in applied mechanics, and the new syllabus of the subject gives unmistakable evidence that he has had much to do with its composition. Prof. Perry has also been appointed an examiner in steam; and Dr. Fream has been appointed an examiner in agriculture. Prof, L. C. Miall's new syllabus of an introductory course of biology should be seen by all who are interested in the teaching of the subject.

THE new Directory of the Department of Science and Art has just been published. Many modifications have been made, both in the regulations for conducting science and art schools and classes, and in the syllabuses of the subjects recognised by the Department. We can only refer to a few of the changes. It is announced for the first time that recognition may be refused to any class which the Department considers to be unnecessary, or to compete unduly with a neighbouring school. This regulation will probably be the means of reducing the undesirable competition which often exists between science classes near one another. Schools may now be managed by a public company, provided that the articles of association specify 5 per cent. per annum as the maximum dividend. Counties and county boroughs which possess an organisation for the promotion of secondary education may elect to be responsible to the Department for the science and art instruction within its area. In such case grants will in general only be made to the managers of new schools and classes if they are acting in unison with the Iocal authority.

A LARGE building, in which the art and technical srhools of Leicester will be incorporated, was opened by the Bishop of London on Tuesday. The cost of the new buildings and site is just under $40,000 l$. The site extends to nearly three-quarters of an acre, and the main frontage is 220 feet, with an elevation of four stories. Two of the floors are devoted to technical instruction in hosiery and boot and shoe manufacture, with a full complement of all kinds of old and new machinery showing the development of the processes of manufacture, engineering, plumbing, dyeing, painting, \&c. The two upper floors will be occupied by the school of arts. A portion of the roof of the building is flat, and on this a conservatory has been erected for studies of plant-life. At the opening ceremony Sir Thomas Wright, chairman of the committee, stated that the whole of the funds for the new building would be provided out of the excise 